\title{
PROIBIÇÃO DE DISCRIMINAÇÃO DA PESSOA COM DEFICIÊNCIA: A INCIDÊNCIA DO PRINCÍPIO DA IGUALDADE NAS RELAÇÕES PRIVADAS
}

\author{
PROHIBITION OF DISCRIMINATION OF PERSONS WITH DISABILITIES: \\ THE INCIDENCE OF THE EQUALITY PRINCIPLE ON PRIVATE RELATIONSHIPS
}

\begin{abstract}
Aletya Dahana Rollwagen
Mestranda do Programa de Pós-Graduação em Direito do Centro Universitário Autônomo do Brasil (UNIBRASIL). Graduada em Direito pelo Centro Universitário do Vale do Iguaçu (UNIGUAÇU) aletya.rollwagen@outlook.com

Rosalice Fidalgo Pinheiro

Doutora em Direito das Relações Sociais junto ao Programa de Pós-Graduação em Direito da Universidade Federal do Paraná (UFPR). Professora de Direito Civil da Faculdade de Direito da Universidade Federal do Paraná (UFPR). Professora do Programa de Pós-Graduação em Direito do Centro Universitário Autônomo do Brasil (UNIBRASIL). Pós-doutora junto à Universidade Paris 1-

Panthéon-Sorbonne. rosallice@gmail.com
\end{abstract}

Resumo: A Constituição Federal tem uma cláusula geral de proibição da discriminação; contudo o tema suscita a incidência do princípio da igualdade no âmbito das relações privadas, o qual é objeto de questionamentos e resistências. No tocante às pessoas com deficiência, o combate à discriminação enfrenta também o desafio de superar a tensão entre igualdade e autonomia privada. O objetivo do presente estudo é analisar os fundamentos e delimitações da vedação da discriminação contra a pessoa com deficiência nas relações privadas. Por meio do método dedutivo e do procedimento de pesquisa documental bibliográfico, constatou-se que a proteção contra a discriminação no ordenamento jurídico brasileiro adota uma perspectiva direta, carecendo de aprofundamento a respeito da proteção contra discriminação indireta. $\mathrm{O}$ Estatuto da Pessoa com Deficiência traz diversas normas que proíbem a discriminação contra a pessoa com deficiência, com incidência expressa sobre as relações privadas, mas a questão ainda é objeto de controvérsias.

Palavras-chave: Pessoa com deficiência. Proibição de discriminação. Relações privadas.

Abstract: The Federal Constitution has a general clause of prohibition of discrimination; however, the theme raises the principle of equality in the context of private relationship, which is subject to questioning and resistance. In regard to persons with disabilities, the opposition to discrimination also faces the challenge of overcoming the tension between equality and private autonomy. The aim of this study is to analyze the fundamentals and boundaries of the prohibition of discrimination against the person with disability in private relationships. Through the deductive method and the documentary bibliographic research approach, using, it was found that the protection against discrimination in the Brazilian legal system adopts a direct perspective, thus lacking get deeper analysis of the protection against indirect discrimination. The Disabilities Persons Act has several rules that prohibit discrimination against a person with a disability, with an express incidence on private relationship, although the issue is still the subject of controversy.

Key-words: Person with disability. Prohibition of discrimination. Private relationship.

\section{Para citar este artigo}

ABNT NBR 6023:2018

ROLLWAGEN, Aletya Dahana; PINHEIRO, Rosalice Fidalgo. Orlando. Proibição de discriminação da pessoa com deficiência: a incidência do princípio da igualdade nas relações privadas. Prisma Jurídico, São Paulo, v. 19, n. 1, p. 174-193, jan./jun. 2020. http://doi.org/10.5585/prismaj.v19n1.16764. 


\section{Introdução}

As "pessoas e os grupos sociais têm o direito a ser iguais quando a diferença os inferioriza, e o direito a ser diferentes quando a igualdade os descaracteriza" (2016, p. 122). Esta afirmação de Boaventura de Sousa Santos sintetiza o direito de não receber tratamento discriminatório nas relações privadas, revelando que o direito à igualdade não comporta tratamentos discriminatórios.

A incidência do direito à igualdade no Direito Privado poderia parecer contraditório. Eis que "discriminar", no sentido de fazer escolhas ou estabelecer diferenças, seria próprio da autonomia privada, desobrigando o particular de justificar suas escolhas. Daí a crítica, segundo a qual a proibição de discriminação resultaria em um aniquilamento da autonomia privada. Entretanto, ao considerar-se que os direitos fundamentais têm eficácia nas relações privadas, a proteção contra discriminação ganha sentido no Direito Privado, passando a se compatibilizar igualdade e autonomia privada.

Essa discussão não escapou à Lei no ${ }^{\circ} 13.146 / 2015$, sendo possível notar em seu conjunto normativo um adensamento do combate à discriminação que tem por fundamento a condição de pessoa com deficiência. Embora a questão já tivesse sido tratada na Convenção Interamericana para a Eliminação de Todas as Formas de Discriminação contra as Pessoas Portadoras de Deficiência (1999) e na Convenção sobre os Direitos das Pessoas com Deficiência (2006), a nova lei delineou em âmbito infraconstitucional a proibição da discriminação dessas pessoas e as diversas formas de sua incidência nas relações privadas.

Voltando-se para esse contexto, o presente artigo busca analisar os fundamentos e delimitações da vedação da discriminação contra a pessoa com deficiência. Revela-se um quadro de normas jurídicas que proíbem sua discriminação, especialmente no que se refere aos contratos de fornecimento de bens e serviços. Para analisar essas situações, utiliza-se o método dedutivo e o procedimento de pesquisa documental bibliográfico, revelando-se uma tensão entre a autonomia privada e a igualdade, que a Lei $\mathrm{n}^{\mathrm{o}}$ 13.146/2015 resolve em favor da pessoa com deficiência.

O plano de trabalho divide-se em três itens, sendo que no primeiro investiga-se como a proibição da discriminação se desenvolveu no cenário europeu e no brasileiro, a partir da valorização do princípio da igualdade e da eficácia dos direitos fundamentais nas relações privadas. No segundo, demonstra-se como a proibição de discriminação surge como princípio postulado pelas diretivas da União Europeia, delineando um direito antidiscriminatório. Posteriormente, indaga-se sobre o acolhimento daquele princípio no Direito Privado, 
notadamente, no direito brasileiro. E no terceiro, a pesquisa volta-se para a proteção em favor das pessoas com deficiência, abordando os mecanismos pelos quais a proibição da discriminação é aplicada nas relações privadas, assim como detalhando algumas das vedações expressamente impostas pelo Estatuto da Pessoa com Deficiência.

\section{Princípio da igualdade: o fundamento da proibição de discriminação no Direito Privado}

Seguindo o pensamento aristotélico de conexão entre igualdade e justiça, é preciso considerar que "a justiça é sempre algo que o indivíduo vivencia, em primeira linha, de forma intersubjetiva e relativa, ou seja, na sua relação com outros indivíduos e na forma como ele próprio e os demais são tratados" (SALES; SARLET, 2020, p. 199).

A igualdade ganhou relevância no constitucionalismo moderno, por meio de sua inclusão nas declarações de direitos e nas primeiras constituições, ainda que não com o mesmo sentido atualmente atribuído a esse princípio (SALES; SARLET, 2020, p. 200). Assim, cabe ressaltar que a palavra "todos", a qual possui um sentido de igualdade, embora recorrente nos textos legais, nem sempre é usada com o mesmo significado, ou seja, não representa que a todo ser humano será assegurado determinado direito (FÁVERO, 2004, p. 28).

No constitucionalismo pós Segunda Guerra Mundial, como reação às práticas discriminatórias realizadas pelos regimes totalitários (RIOS; LEIVAS, 2017, p. 129), a igualdade passou por uma expansão quantitativa e qualitativa, especialmente no direito internacional, mantendo sua importância no constitucionalismo contemporâneo (SALES; SARLET, 2020, p. 200-201).

Os documentos internacionais e supranacionais incorporaram, além de uma cláusula geral de igualdade, cláusulas especiais, voltando-se para o combate de diferentes formas de discriminação (SALES; SARLET, 2020, p. 201). Nesse contexto, pode-se destacar a Convenção Internacional sobre a Eliminação de Todas as Formas de Discriminação Racial (1965), a Convenção sobre a Eliminação de Todas as Formas de Discriminação contra a Mulher (1979), a Convenção Interamericana para a Eliminação de Todas as Formas de Discriminação contra as Pessoas Portadoras de Deficiência (1999) e a Convenção sobre os Direitos das Pessoas com Deficiência (2006).

Nesse cenário, é possível perceber que o princípio da igualdade passou por mudanças que podem ser divididas em três diferentes fases: a igualdade perante a lei (prevalência da lei igualdade formal), a igualdade da própria lei (na lei) e a igualdade como proibição de discriminação (SALES; SARLET, 2020, p. 202-203). 
$\mathrm{Na}$ primeira fase, a igualdade não impedia o estabelecimento de desigualdades em direitos e obrigações, apenas vinculava os órgãos que aplicavam o direito às normas criadas pelo legislador, sem vincular a atuação deste (ALEXY, 2008, p. 394-395). No Direito Privado, essa atuação se faz presente na relação entre igualdade e codificação. Em oposição à pluralidade de fontes, o Código Civil despontou como a lei geral e abstrata, que submetia todos os indivíduos a um único ordenamento jurídico - o "estatuto dos sujeitos iguais” (IRTI, 1999, p. 25). Avulta a igualdade formal, que operava como um instrumento para ruptura das desigualdades jurídicas estabelecidas pelo particularismo jurídico.

$\mathrm{Na}$ segunda fase, que pode ser chamada de igualdade material, exige-se que critérios razoáveis e justos sejam utilizados para definir tratamentos desiguais (SALES; SARLET, 2020, p. 205). Assim, considerando que é inviável exigir tratamento igual para todos, em todos os aspectos (sob pena de serem criadas normas injustas e sem sentido), mas que também é inaceitável permitir toda diferenciação, a vinculação do legislador não é apenas em relação à forma lógica das normas, como também ao seu conteúdo (ALEXY, 2008, p. 399). Diante disso, a igualdade dos indivíduos perante a lei é rompida em favor de uma intervenção estatal, que, sob a técnica das leis especiais, legisla para grupos mais vulneráveis da sociedade. O Código Civil perde espaço em face da Constituição, que acolhe a incidência dos direitos fundamentais nas relações privadas.

A terceira fase, chamada de igualdade social ou de fato, compreende também um dever de compensar as desigualdades culturais, econômicas e sociais (SALES; SARLET, 2020, p. 205). Assim, o princípio da igualdade compreende a proibição do tratamento arbitrário devendo haver uma justificativa razoável para que os tratamentos sejam diferenciados ou iguais - a proibição de discriminação e a obrigação de tratamento diferenciado para compensar as desigualdades (SALES; SARLET, 2020, p. 207). Busca-se proteger a pessoa concreta, de acordo com suas diferenças, tornando-se uma exigência o direito de não receber tratamento discriminatório nas relações privadas.

Os juízos sobre igualdade e desigualdade sempre levam em consideração determinada característica daqueles que são comparados, tratando-se, portanto, de uma igualdade ou desigualdade fática parcial. Contudo, nem todas as características podem ser utilizadas para justificar diferenciação de tratamento. Nesse contexto, Robert Alexy defende que a possibilidade de tratamento diferenciado é condicionada pelas igualdades fáticas parciais (não uma simples igualdade valorativa dos indivíduos), em relação a determinados tratamentos (uma característica não pode justificar tratamento igual/desigual em todos os aspectos), a partir de um critério de valoração (ALEXY, 2008, p. 399-400). 
O que é vedado é o tratamento arbitrariamente desigual, isto é, aquele que não é fundado em uma razão suficiente que justifique a diferenciação. Portanto, a cláusula geral de igualdade impõe um ônus argumentativo para o tratamento desigual: "um princípio da igualdade que prima facie exige um tratamento igual e que permite um tratamento desigual apenas se isso for justificado por princípios contrapostos" (ALEXY, 2008, p. 408-411), num juízo de proporcionalidade que considere a finalidade legítima a ser alcançada e a necessidade e adequação dos meios utilizados (RULL, 2007, p. 14-16).

Da mesma forma, as cláusulas especiais de igualdade não impedem que determinados critérios sejam, justificadamente, utilizados para estabelecer tratamento desigual, contudo elas impõem um ônus argumentativo maior, sempre considerando a legitimidade constitucional da finalidade do ato (SALES; SARLET, 2020, p. 210-211).

Na sua dimensão subjetiva, o direito à igualdade é fundamento de posições individuais negativas e positivas, que se destinam, primeiramente, aos órgãos estatais. $\mathrm{Na}$ ordem jurídica privada, esse princípio incide sobre a atividade do legislador, que atua mediando a aplicação das cláusulas de igualdade nas relações privadas, e também sobre "atores privados dotados de poder social" que exploram atividades abertas ao público (SALES; SARLET, 2020, p. 208209), ou seja, como mecanismo de correção dos desequilíbrios de poder contratual (INFANTE RUIZ, 2013, p. 201).

Ainda que não exista uma cláusula geral expressa de proibição de discriminação no Direito Privado, pode-se defender a existência de um princípio implícito nesse ramo do direito, em especial porque "exercer a liberdade de contratar ou a liberdade contratual, violando o direito fundamental à igualdade de tratamento [...] é atentar contra a função social do contrato" (PINHEIRO, 2014, p. 67-68).

Assim, defende-se a eficácia dos direitos fundamentais na ordem privada, com o objetivo de promoção da igualdade e da liberdade material, compensando as desigualdades de poder, pois mesmo as relações entre particulares são, de certo modo, verticalizadas (ainda que se fale em eficácia horizontal), quando se tem diferenças expressivas de poder social entre os particulares (SARLET, 2006, p. 580).

No âmbito da discussão a respeito da proteção contra a discriminação, no entanto, o desequilíbrio da relação, isto é, a vulnerabilidade de um dos contratantes, pode decorrer do próprio pertencimento a um grupo socialmente excluído (PINHEIRO, 2014, p. 62).

Nesse contexto, a existência de um mandamento antidiscriminatório ensejou o desenvolvimento de legislação e jurisprudências específicas do "direito da antidiscriminação" e do "direito de minorias", tanto em âmbito nacional como internacional, as quais são marcadas 
por "avanços, retrocessos e tensões, que eclodem na busca pela transformação de estruturas e de práticas injustas" (RIOS, LEIVAS, SCHÄFER, 2017, p. 128.).

A incidência dos direitos humanos nas relações privadas causa questionamentos, uma vez que os sujeitos são igualmente titulares de direitos humanos ou fundamentais. Embora a vedação de certas discriminações seja indiscutivelmente um direito humano e, em diversas constituições, um direito fundamental, sua proteção absoluta é um ataque desarrazoado à autonomia privada (SILVA, 2007, p. 390). Em razão disso, a eficácia dos direitos fundamentais nas relações privadas provoca tensões que não podem ser resolvidas pela lógica do tudo ou nada, mas à luz da proporcionalidade (SILVA, 2007, p.586).

Em mesmo sentido, Francisco José Infante Ruiz afirma que a proteção contra a discriminação representa uma tensão entre o princípio da liberdade contratual e o princípio da igualdade de tratamento (INFANTE RUIZ, 2013, p. 3). As críticas à existência de uma proteção contra a discriminação no Direito Privado elegem a autonomia privada como um valor absoluto, desconsiderando que a tutela constitucional à autonomia privada é vinculada à dignidade da pessoa humana (PINHEIRO, 2014, p. 62).

Para Ingo Wolfgang Sarlet, a relação entre Constituição, direitos fundamentais e Direito Privado sempre seguiu uma lógica dialética e dinâmica de influência recíproca. A constitucionalização do direito ocorre por duas vias: por um lado "a presença da Constituição no Direito Privado, onde se cuida da influência das normas constitucionais [...] sobre as normas do Direito Privado e as relações entre particulares"; de outro lado "a presença do Direito Privado na Constituição, onde se cuida de institutos originalmente do Direito Privado previstos na Constituição" (SARLET, 2006, p. 576-577).

Apesar dessa tensão entre liberdade e igualdade e da existência de defensores de um afastamento da participação ativa do Estado no Direito Privado, é inegável que, no estágio do direito positivo atual, muitos países possuem regras específicas de combate à discriminação do âmbito privado. Defender a inexistência dessas normas, além de ser de pouca utilidade, implica em desconsiderar as causas de discriminação e o tempo necessário para que o livre mercado atue sobre discriminações graves (SILVA, 2007, p. 391).

Nesse aspecto, Rosalice Fidalgo Pinheiro leciona a respeito do atual contexto da relação entre autonomia privada e discriminação: 
De uma "hipertrofia da autonomia da vontade" que permitia ao homem realizar-se como pessoa e afirmar sua liberdade individual, a autonomia privada é redesenhada em face da possibilidade de aplicação direta das normas constitucionais. Invocandose a tutela constitucional, o princípio passa a encontrar significado em sua funcionalização. Nesta perspectiva, dissipa-se a tensão entre autonomia privada e discriminação, pois o exercício da liberdade contratual pode caracterizar discriminação por atentar contra os direitos fundamentais $(2014$, p. 78).

Aqui, é importante ressaltar que a distinção entre o direito da antidiscriminação e o direito de minorias, mencionada anteriormente, demonstra que as normas jurídicas, embora orientadas pelo princípio da igualdade, possuem diferentes estruturas, abrangência subjetiva e modalidades de resposta (RIOS; LEIVAS; SCHÄFER, 2017, p. 130-131).

O direito de minorias diz respeito ao direito internacional e aos direitos humanos voltados à proteção de "minorias nacionais ou étnicas, culturais, religiosas e linguísticas", isto é, a grupos específicos, enquanto que o direito da antidiscriminação abrange instrumentos normativos nacionais e internacionais "relativos ao direito à igualdade como mandamento proibitivo de discriminação", e destinados a proteger todos os seres humanos (RIOS; LEIVAS; SCHÄFER, 2017, p. 131-133).

Assim, percebe-se que existe uma diferença em relação à abrangência subjetiva da proteção, pois o direito de minorias protege o grupo como um ente distinto, com existência e identidades próprias e distintas da soma de indivíduos que o compõe. Essa característica pode ser identificada tanto na Declaração dos Direitos das Pessoas pertencendo a Minorias Nacionais ou Étnicas, Religiosas e Linguísticas, como na Convenção para a Prevenção e a Repressão do Crime de Genocídio (RIOS; LEIVAS; SCHÄFER, 2017, p. 134-135).

Nesse contexto, o direito de minorias adota uma perspectiva particularista, em contraposição ao direito da antidiscriminação, que se volta à proteção do sujeito de direito, considerado de forma universal e abstrata. Para o direito de minorias, apenas reforçar o mandamento antidiscriminatório pela enumeração de critérios proibidos não é suficiente (RIOS; LEIVAS; SCHÄFER, 2017, p. 135-136).

Tanto o direito da antidiscriminação como o direito das minorias possuem medidas repressivas da discriminação e deveres de proteção estabelecidos aos Estados e à comunidade internacional, porém com propósitos distintos: o primeiro busca promover a igualdade de exercício de direitos reconhecidos a todos, enquanto o segundo se destina à promoção da identidade do grupo minoritário (RIOS; LEIVAS; SCHÄFER, 2017, p. 136). 


\section{A proibição de discriminação nas relações privadas}

A discriminação é combatida no âmbito da União Europeia desde 1975. Contudo, por meio das diretivas 2000/43/CE e 2004/113/CE, que tratam, respectivamente da discriminação racial e entre homens e mulheres, passou-se a adotar um enfoque transcendental, ampliando a aplicação do princípio da igualdade ao acesso a bens e serviços nas relações contratuais entre sujeitos privados (INFANTE RUIZ, 2013, p. 5-7).

Um marco do direito antidiscriminatório europeu é o Tratado de Amsterdã, de 1997, que incluiu no Tratado Constitutivo da União Europeia um artigo contra a discriminação, ampliando os motivos considerados ilícitos para além da nacionalidade e do sexo, incluindo raça, origem étnica, orientação sexual e deficiência (INFANTE RUIZ, 2013, p. 4).

A diretiva 2004/113/CE, embora subordine a liberdade das seguradoras à igualdade em razão do sexo, admite que os Estados autorizem a diferenciação de prêmios e prestações, quando o sexo for fator determinante para avaliação dos riscos. Essa exceção é criticada por sua incompatibilidade com o valor de luta contra a discriminação por razões de gênero presente no direito originário comunitário. A questão foi analisada pelo Tribunal de Justiça da União Europeia, o qual entendeu que o artigo 5.2 da diretiva deve ser anulado, pois existe o risco do direito da União Europeia permitir a exceção à igualdade indefinidamente, além dessa previsão ser incompatível com a consecução do objetivo da diretiva e com os artigos 21 e 23 da Carta de Direitos (INFANTE RUIZ, 2013, p. 10-13).

Francisco José Infante Ruiz ressalta que, no direito espanhol, a Lei Orgânica 3/2007 incorporou as diretivas comunitárias, merecendo destaque o art. 69, o qual combate a discriminação direta e indireta, e exige o cumprimento do princípio da igualdade de tratamento entre homens e mulheres por "todas las personas físicas o jurídicas que, en el sector público o en el privado, suministren bienes o servicios disponibles para el público, ofrecidos fuera del ámbito de la vida privada y familiar" (INFANTE RUIZ, 2013, p. 16-17).

Em um estudo sobre a aplicação da Lei Orgânica 3/2007, o Conselho Geral do Poder Judiciário constatou que os juízes citavam pouco e não desenvolviam a interpretação da mencionada lei no âmbito trabalhista. No âmbito dos contratos civis, a aplicação é quase inexistente, tanto que sequer é analisada pelo estudo (INFANTE RUIZ, 2013, p. 21).

No entanto, deve ser ressaltada a Sentença do Tribunal Supremo de 20 de abril de 2011 (RJ 2011/3596), a qual abordou o tema da proibição da discriminação em razão de sexo, tratando como princípio fundamental da União Europeia o princípio da igualdade e a proibição da discriminação. Nesta sentença, o Tribunal fixou o entendimento de aplicação da inversão do 
ônus da prova em relação ao motivo do ato quando o demandante apresentar indícios razoáveis (fumus boni iuris) de discriminação (INFANTE RUIZ, 2013, p. 21-24).

Já no Brasil, a proteção contra a discriminação não decorre de leis ordinárias ou de disposições como as diretivas anteriormente mencionadas, e sim diretamente da Constituição (SILVA, 2007, p. 392). É possível constatar claramente a existência de uma cláusula geral de igualdade (art. $5^{\circ}$, caput, da Constituição) ao lado de cláusulas e direitos especiais, voltados a determinados grupos de pessoas ou circunstâncias, como às mulheres, às relações de filiação e trabalho, entre outros (SALES; SARLET, 2020, p. 206). Sob o prisma jurídico, a discriminação é "o elemento de uma política, que leva em conta, entre os diversos tratamentos injustificadamente diferenciados, apenas aqueles que possuem significância social" (SILVA, 2007, p. 392).

As normas antidiscriminatórias possuem fundamentos de ordem individual e coletiva. Na perspectiva individual, elas são consequência do princípio da igualdade e proteção à dignidade, preservando o indivíduo de atos que limitam injustificadamente seus direitos individuais. Já na perspectiva coletiva, surge a compreensão de que os atos individuais de discriminação refletem uma compreensão socialmente difundida de inferioridade de determinado grupo, de forma que as normas antidiscriminatórias buscam romper essa hierarquização social (SILVA, 2007, p. 394-395).

No Brasil, existe um catálogo aberto de sinais protegidos de discriminação, sendo alguns deles expressamente elencados nos art. $3^{\circ}, 5^{\circ}$ e $7^{\circ}$ da Constituição Federal. $\mathrm{O}$ critério para complementar esse catálogo não é unânime, porém o critério do preconceito, além de estar expressamente mencionado no art. $3^{\circ}$, inciso IV, pressupõe "um determinado grau de significado social para que o específico sinal seja incluído na lista” (SILVA, 2007, p. 399).

As modalidades de discriminação podem ser classificadas em discriminação direta, indireta e assédio: na discriminação direta o sinal discriminatório é causa de tratamento menos favorável do que aquele prestado a outra pessoa em situação comparável; na discriminação indireta cria-se uma situação de desvantagem aos portadores de sinais de discriminação a partir de um critério aparentemente neutro; no assédio, moral ou sexual, o sinal de discriminação se vincula a um comportamento indesejado, que viola a dignidade e cria um ambiente de hostilidade, humilhação. Enquanto a vedação da discriminação direta e do assédio volta-se especialmente para a proteção do indivíduo, a vedação da discriminação indireta enfatiza a proteção do grupo (SILVA, 2007, p.401-402).

No ordenamento jurídico brasileiro, a extinção de discriminações não é apenas uma decorrência do princípio da igualdade e da proteção geral dos direitos fundamentais, pois foi 
incluída no catálogo de objetivos fundamentais da República Federativa do Brasil como condição necessária ao bem-estar geral (SILVA, 2007, p.406). A distinção entre discriminação direta e indireta tem sido aceita de forma ampla, aliada à compreensão de que ambas são modalidades que ofendem o princípio da igualdade, quando não houver justificativa constitucional (SALES; SARLET, 2020, p. 212).

Nesse cenário, os direitos fundamentais influenciam diretamente na validade dos negócios jurídicos e na licitude das condutas, podendo inclusive gerar o dever de indenizar outrem pela violação desses direitos (SILVA, 2007, p. 408).

Embora não se negue a possibilidade de "extrair deveres aos privados diretamente dos direitos fundamentais", a questão também envolve a discussão a respeito dos limites a essa incidência, especialmente no tocante à preservação do núcleo essencial da autonomia privada. Os tribunais brasileiros adotaram o posicionamento que defende a necessidade de ponderação de direitos fundamentais, permeada pela aplicação direta. Nesse contexto, embora não existam respostas prontas, cabe ressaltar que a autonomia privada possui grande relevância, a qual, entretanto, é diminuída "quando uma das partes contratuais é digna de especial proteção" (SILVA, 2007, p. 409-410).

Por outro lado, o próprio Direito Privado possui mecanismos que promovem a aplicação indireta dos direitos fundamentais nas relações privadas. Entre eles: a proteção aos direitos de personalidade que permite que se exija a cessação de atos ou ameaças de violação, como "publicidade discriminatória, ofertas discriminatórias de emprego" (SILVA, 2007, p.410-411); a indenizabilidade do dano extrapatrimonial, que reduz a necessidade de medidas mais interventivas, como a imposição do dever de contratar; a obrigação de contratar, aplicável nas relações de consumo, em razão da vinculatividade da oferta; a declaração de invalidade de negócios jurídicos ou cláusulas contratuais discriminatórias; e, no âmbito trabalhista, a demissão por justa causa e a rescisão indireta pela prática de atos discriminatórios (SILVA, 2007, p.411-415).

Diante do exposto, é possível perceber que, no direito brasileiro, a proteção contra discriminação é concentrada na perspectiva individual, sem aprofundar o debate sobre as limitações à autonomia privada e os instrumentos de proteção coletiva (SILVA, 2007, p. 397 398). Ocorre que, sob a perspectiva de um modelo grupal/coletivo de proteção antidiscriminatória, apenas o combate à discriminação individual não é suficiente para a concretização do direito à igualdade (RIOS; LEIVAS; SCHÄFER, 2017, p. 139). Assim: 


\begin{abstract}
A qualificação de um grupo como sujeito de direito protegido pelo direito da antidiscriminação (aqui compreendidos os grupos minoritários enquanto sujeitos coletivos) traz à baila questões como a proteção permanente, e não só pontual, do respectivo grupo, o reconhecimento de um status jurídico próprio (ao qual se atribui uma identidade que vai além de propósitos econômicos e de posições definidas em relações de consumo) [...] (RIOS; LEIVAS; SCHÄFER, 2017, p. 140).
\end{abstract}

Nesse contexto, ganha relevância a atuação estatal por meio de políticas afirmativas, como forma de combate à discriminação indireta, em razão do impacto desproporcional de determinadas práticas sobre categorias específicas de pessoas. A previsão constitucional de medidas voltadas à redução das desigualdades permite concluir pela existência de um dever de realizar políticas afirmativas, sob pena de caracterizar um "estado de omissão inconstitucional" (SALES; SARLET, 2020, p. 212-213). Jorge Cesa Ferreira da Silva defende a necessidade de uma lei geral antidiscriminação, a fim de ensejar o aprofundamento do debate a respeito do tema, além de aprimorar a proteção contra a discriminação indireta, a qual exige a intervenção legislativa (SILVA, 2007, p. 416).

\title{
4 A proibição de discriminação da pessoa com deficiência nas relações privadas
}

A deficiência é um traço identitário, comumente associado a uma parcela minoritária da população, cercado por afirmações tradicionalmente paternalistas e assistencialistas. Ela não pode ser utilizada como justificativa para práticas discriminatórias, salvo aquelas de natureza positiva (SALES; SARLET, 2020, p.198).

Ocorre que a discriminação contra a pessoa com deficiência é, muitas vezes, tratada como algo "natural" e internalizada pelas próprias pessoas com deficiência como algo inerente à sua condição (FEMINELLA; LOPES, 2016, p. 24). O estigma da deficiência, aliado à falta de conhecimento da sociedade, dificulta o convívio social e a prática de atos corriqueiros, como a obtenção de emprego, acesso à saúde e à educação (MARTA, 2009, p. 8).

Dentre as práticas recorrentes, pode-se citar o impedimento de acesso a transporte público, eventos e atividades abertas ao público, algumas vezes decorrentes da própria falta de acessibilidade; a recusa de matrícula em instituição de ensino e a não oferta de medidas de acessibilidade para a inclusão nas atividades escolares; recusa de atendimento médico; impedimento de acesso à mesa de votação; recusa de contratação de profissional qualificado, em razão da deficiência; negação do direito de denúncia e autodefesa por ausência de intérprete de Libras (FEMINELLA; LOPES, 2016, p. 24).

A Convenção sobre os Direitos das Pessoas com Deficiência, recepcionada com status de emenda constitucional (art. $5^{\circ}, \S 3^{\circ}$, da Constituição Federal), estabeleceu um conceito de 
discriminação em seu artigo 2:

[...] "Discriminação por motivo de deficiência" significa qualquer diferenciação, exclusão ou restrição baseada em deficiência, com o propósito ou efeito de impedir ou impossibilitar o reconhecimento, o desfrute ou o exercício, em igualdade de oportunidades com as demais pessoas, de todos os direitos humanos e liberdades fundamentais nos âmbitos político, econômico, social, cultural, civil ou qualquer outro. Abrange todas as formas de discriminação, inclusive a recusa de adaptação razoável; $[\ldots]$

Esse conceito segue a mesma concepção do conceito adotado no art. I da Convenção Interamericana para a Eliminação de Todas as Formas de Discriminação contra as Pessoas Portadoras de Deficiência, o qual ainda esclarece que a discriminação pode se basear também em "antecedente de deficiência, consequência de deficiência anterior ou percepção de deficiência presente ou passada".

A discussão a respeito de um direito antidiscriminatório no âmbito dos direitos das pessoas com deficiência, ganha relevância diante da mudança paradigmática do conceito de pessoa com deficiência. A perspectiva biomédica, marcadamente individual, que acarretava uma abordagem estigmatizante, foi substituída pelo modelo social, que compreende a deficiência a partir de uma perspectiva sociológica e política, de maneira que exige "a criação de políticas públicas que visem a transformação de todas as espécies de padrões sociais excludentes" (SALES; SARLET, 2020, p. 214-215).

Contudo, a busca pela padronização a fim de atingir o ideal de perfeição ainda é uma situação presente na sociedade, e prejudica a luta pela inclusão dos diferentes. Nesse contexto, ressalta-se a importância do direito à antidiscriminação, pois a ideologia da normalidade gera uma discriminação silenciosa, que apela aos sentimentos íntimos e inconscientes, fazendo com que as pessoas ajam de forma discriminatória acreditando que fazem bem à pessoa com deficiência. $\mathrm{O}$ direito à igualdade deve ser compreendido também como direito à diferença e, especialmente, como fundamento do direito à inclusão (SALES; SARLET, 2020, p. 220-221).

A Convenção sobre os Direitos das Pessoas com Deficiência, além de conceituar a discriminação, estabelece, no art. 5, o dever de proibição geral da discriminação baseada na deficiência. No mesmo artigo, ainda está previsto o dever de adotar medidas voltadas à garantia de adaptação razoável, e a exclusão do conceito de discriminação de medidas que se destinem à efetiva igualdade das pessoas com deficiência.

Em relação às pessoas com deficiência, a Convenção sobre os Direitos das Pessoas com Deficiência e as normas nacionais que dela decorrem (a exemplo do Estatuto da Pessoa com Deficiência - Lei $\left.n^{\circ} 13.146 / 15\right)$, estabelecem parâmetros que vinculam também as relações 
entre particulares (SALES; SARLET, 2020, p. 209). A proteção contra a discriminação em face da pessoa com deficiência pode, inclusive, ensejar a responsabilização criminal.

Nesse sentido, constitui crime punível com pena de reclusão de 1 (um) a 3 (três) anos, e multa à prática, indução ou incitação de discriminação em razão de deficiência. Quando o crime for praticado em meios de comunicação social ou publicação, a pena será de 2 (dois) a 5 (cinco) anos, cumulativamente à multa. Além disso, o conteúdo discriminatório pode ser recolhido/apreendido ou ter seu acesso interditado, caso veiculado na internet, para posterior destruição (art. 88 da Lei no 13.146/2015).

Contudo, é possível perceber a existência de controvérsias em relação ao direito da antidiscriminação aplicado às relações contratuais privadas, em razão dos casos que chegam aos tribunais brasileiros envolvendo práticas discriminatórias no âmbito de planos de saúde, seguros com cláusula de perfil do segurado e contratos de financiamento habitacional (PINHEIRO, 2014, p. 53).

O problema se acentua face à proteção mitigada oferecida pela jurisprudência brasileira, a qual, diante da tensão envolvendo a igualdade/não-discriminação frente à liberdade contratual e autonomia privada, dá prevalência a estas últimas (PINHEIRO, 2014, p. 53).

Nesse aspecto, deve-se considerar o atual contexto social, em que o avanço da globalização provocou aumento dos níveis de exclusão social e opressão, o que revela a atualidade da discussão sobre a eficácia social da Constituição e dos direitos fundamentais para além das relações que envolvem o Estado - a dignidade da pessoa humana e os direitos fundamentais se aplicam a toda a ordem jurídica e social (SARLET, 2006, p. 578).

A proibição de discriminação no contrato pode se manifestar, em âmbito infraconstitucional, por meio de normas que impõem o dever de contratar, deveres de omissão, além de consequências como a indenização por danos extrapatrimoniais, a invalidade de cláusulas contratuais e o inadimplemento das obrigações (PINHEIRO, 2014, p. 70).

O dever de contratar no âmbito do direito do consumidor protege as pessoas "contra recusas contratuais discriminatórias", a exemplo das que envolvem pessoas com deficiência, pois a relação de consumo não depende, na maioria das vezes, das qualidades pessoais do consumidor (SILVA, 2007, p. 414).

Por outro lado, em contratos como o de locação e de compra e venda de imóveis, nos quais existe uma escolha dos contratantes em relação à outra parte do contrato, poderia se argumentar a exclusão da possibilidade de discriminação. Contudo, deve-se atentar para o fato de que haverá discriminação caso se verifique o impedimento de acesso das pessoas com deficiência a bens essenciais (PINHEIRO, 2014, p. 61). 
A nulidade de uma cláusula pode ser decretada, por exemplo, no caso de "elevação exagerada do prêmio do seguro-saúde", se ela tiver caráter discriminatório ou excludente (SILVA, 2007, p. 415). Ainda, nos contratos de seguro, a recusa de contratação e a resolução do contrato podem indicar a existência de uma discriminação indireta (PINHEIRO, 2014, p. $61)$.

A recusa discriminatória de contratação, sem que se trate de relação de consumo, mesmo não havendo uma imposição de contratação, pode dar direito à indenização por perdas e danos (PINHEIRO, 2014, p. 70).

A imposição de deveres de omissão corresponde à tutela inibitória prevista no Código Civil (arts. 12 e 21), a fim de cessar ameaça ou lesão aos direitos de personalidade. No âmbito das relações de consumo, a publicidade discriminatória é considerada abusiva e, portanto, proibida (art. 37, $\S 2^{\circ}$, do Código de Defesa do Consumidor), ensejando tanto a imposição de abstenção como o dever de indenizar (PINHEIRO, 2014, p. 70-71).

A vinculação dos particulares aos direitos fundamentais é, a princípio, direta, pois não depende da mediação do legislador (SARLET, 2006, p. 585). Contudo, da análise da jurisprudência brasileira sobre discriminação nos contratos é possível constatar que os casos são, em regra, resolvidos pela revisão do contrato, nulidade de cláusulas e limitação do direito de denúncia. A fundamentação das decisões recorre a previsões expressas da legislação infraconstitucional, ainda que a proibição constitucional de discriminação (art. $3^{\circ}$, inciso IV, da Constituição) levasse à mesma solução (PINHEIRO, 2014, p. 77).

Diante disso, é relevante ressaltar as previsões infraconstitucionais de proteção contra a discriminação das pessoas com deficiência. Não obstante, deve-se mencionar que a Convenção sobre os Direitos das Pessoas com Deficiência, que foi incorporada ao ordenamento jurídico brasileiro com status de emenda constitucional, não apenas inspirou a legislação infraconstitucional, como elencou cláusulas específicas de proibição de discriminação em relação à pessoa com deficiência.

A Lei n ${ }^{\circ} 13.146 / 2015$, também conhecida como Estatuto da Pessoa com Deficiência ou Lei Brasileira de Inclusão da Pessoa com Deficiência estabeleceu a vedação da discriminação “inclusive por meio de cobrança de valores diferenciados por planos e seguros privados de saúde, em razão de sua condição" (artigo $28, \S 1^{\circ}$ ). Assim, não é apenas a recusa de inclusão em plano de assistência médica em razão da condição de pessoa com deficiência que é vedada (art. 14 da Lei no 9.656/98) (MARTA, 2009, p. 14). Destaque-se que essa proibição está em consonância com o dever assumido pela adesão à Convenção sobre os Direitos das Pessoas com Deficiência, a qual impõe, em seu art. 25, alínea "e", que os Estados Partes proíbam a 
discriminação na provisão de seguros de saúde e de vida.

Outra situação que envolve a contratação de planos e seguros de saúde é a exigência de declaração de saúde. Diante dessa exigência, o consumidor tem a obrigação de prestar informações verdadeiras, pois a omissão ou falsidade pode ensejar a suspensão ou rescisão do contrato. Por outro lado, exigir que a pessoa declare ser deficiente, a fim de delimitar a fruição de direitos, pode ser considerada uma atitude discriminatória (MARTA, 2009, p. 15-18).

O Estatuto da Pessoa com Deficiência criminalizou a conduta de impedir ou dificultar o ingresso de pessoa com deficiência em planos privados de assistência à saúde, o que se caracteriza inclusive com a cobrança de valores diferenciados, ao acrescentar o $\S 3^{\circ}$ ao art. $8^{\circ}$ da Lei $n^{\circ} 7.853 / 89$, reforçando a proteção contra esse tipo de discriminação.

Em relação aos prestadores de serviços de educação, o Estatuto da Pessoa com Deficiência estendeu expressamente às instituições privadas as obrigações contidas nos incisos I, II, III, V, VII, VIII, IX, X, XI, XII, XIII, XIV, XV, XVI, XVII e XVIII do artigo 28 do referido Estatuto. Dentre essas obrigações destaca-se a oferta de serviços e recursos de acessibilidade, a disponibilização de professores de atendimento especializado, tradutores, intérpretes de Libras e profissionais de apoio. Ainda, a instituição não pode cobrar valores adicionais em mensalidades, anuidades e matrículas para o cumprimento dessas determinações, conforme disposto no $\S 1^{\circ}$ do art. 28 do Estatuto, sendo que tal prática pode ensejar inclusive sanção penal de 2 a 5 anos e multa (art. $8^{\circ}$, inciso I, da Lei $n^{\circ} 7.853 / 89$ ).

A respeito do tema, demonstrando a histórica resistência dos estabelecimentos de ensino ao recebimento de alunos com deficiência nas salas de aula comuns, a Confederação Nacional dos Estabelecimentos de Ensino - Confenen ajuizou a Ação Direta de Inconstitucionalidade $n^{\circ}$ 5357/DF, afirmando que a obrigatoriedade de oferecimento de atendimento educacional adequado e inclusivo às pessoas com deficiência em escolas privadas viola aos artigos $5^{\circ}$, caput, incisos XXII, XXIII, LIV, 170, incisos II e III, 205, 206, caput, incisos II e III, 208, caput, inciso III, 209, 227, caput, $\S 1^{\circ}$, inciso II, todos da Constituição da República Federativa do Brasil (BRASIL, 2017).

Os argumentos utilizados pela Confenen foram de que a obrigação de atendimento educacional especializado é exclusiva do Estado, o qual estaria transferindo-a para as escolas privadas, bem como de que os recursos necessários para que os alunos com deficiência fossem recebidos sem discriminação tornariam muito onerosa a atividade dessas escolas, levando ao encerramento de muitos estabelecimentos, além de prejudicar os demais alunos. Ainda afirma que o direito de propriedade e sua função social seriam violados, assim como a liberdade de aprender e de ensinar, o pluralismo de ideias e de concepções pedagógicas, a coexistência de 
instituições públicas e privadas, a liberdade à iniciativa privada, e os direitos dos profissionais, que teriam sofrimento psíquico ao receberem alunos com deficiência (BRASIL, 2017).

O Supremo Tribunal Federal entendeu, por maioria de votos, pela constitucionalidade dos artigos questionados, levando em consideração que a Convenção Sobre os Direitos da Pessoa com Deficiência possui status de emenda constitucional, por força de sua aprovação seguindo o procedimento previsto no artigo $5^{\circ}, \S 3^{\circ}$ da Constituição Federal, e exige a observação ao princípio da igualdade, no respeito à dignidade humana, além de prever explicitamente o ensino inclusivo em todos os níveis de educação. O relator, ministro Luiz Edson Fachin, ainda ressaltou que o Estado atua na inclusão das pessoas com deficiência em uma dupla via, considerando o direito das pessoas com deficiência, mas também o direito de todos os demais cidadãos ao acesso à vida democrática, da qual a pluralidade é elemento essencial (BRASIL, 2017).

Nesse sentido, pela elaboração da Lei $n^{\circ} 13.146 / 2015$, o compromisso de proteção e ampliação dos direitos das pessoas com deficiência seria atendido, e mesmo que o serviço público de educação seja livre à iniciativa privada, não dependendo de concessão ou permissão, as instituições privadas devem cumprir as normas gerais da educação nacional, nos termos do artigo 209, inciso I, da Constituição Federal. O relator também ressaltou que "à escola não é dado escolher, segregar, separar, mas é seu dever ensinar, incluir, conviver" (BRASIL, 2017).

O ministro Marco Aurélio Mendes de Farias Mello, por sua vez, proferiu voto no sentido de que "não se faz milagre no campo econômico-financeiro" (BRASIL, 2017). Para ele, sob a égide de uma Constituição democrática, não se pode exigir da iniciativa privada uma obrigação que ao Estado não é imposta, pois considera que, no campo da educação, este é o principal obrigado.

Também cabe destacar o voto da ministra Rosa Weber, que ressaltou que os custos necessários à implementação da acessibilidade e da qualidade de ensino para pessoas com deficiência devem ser incorporados aos custos totais das escolas e diluídos entre todos os alunos. A ministra ainda afirmou que, nos termos do artigo 227 da Constituição Federal, assegurar à criança, ao adolescente e ao jovem, com absoluta prioridade, o direito à educação, é dever da família, do Estado e também da sociedade (BRASIL, 2017). Portanto, os custos adicionais devem integrar o orçamento geral da instituição, que é obrigada a fornecer estrutura adequada a todos os seus alunos (MINISTÉRIO PÚBLICO FEDERAL, 2004, p. 24).

Conjugando as disposições dos artigos $4^{\circ}$ e 28 , da Lei 13.146/2015 com o pronunciamento, acima apontado, do Supremo Tribunal Federal, é possível afirmar que há a proibição de discriminação das pessoas com deficiência nos contratos de prestação de serviços 
educacionais. Eis que o Estatuto garante o direito à educação, em uma percepção inclusiva, impondo às instituições privadas o dever de atender às exigências de acessibilidade e a proibição de cobrança de valores adicionais em mensalidades, matrículas ou anuidades (TRAUTWEIN; PINHEIRO, 2017, p. 209).

Além dos serviços de saúde e educação, o Estatuto da Pessoa com Deficiência também conferiu especial proteção contra a discriminação nos serviços de táxi, nos termos do art. 51 da referida lei, impondo às empresas de táxi a obrigação de garantir que $10 \%$ de sua frota seja acessível, além de proibir a cobrança diferenciada pelos serviços prestados à pessoa com deficiência.

Da mesma forma, as locadoras de veículos possuem a obrigação de oferecer um veículo adaptado para uso de pessoa com deficiência a cada 20 veículos de sua frota, nos termos do art. 52 do Estatuto da Pessoa com Deficiência.

Ainda, o Estatuto impõe às construtoras e incorporadoras responsáveis pelo projeto e construção de edificações de uso privado multifamiliar a obrigação de assegurar percentual mínimo de unidades internamente acessíveis, vedando a cobrança de valores adicionais para aquisição dessas unidades, no artigo 32.

\section{Considerações finais}

A pesquisa demonstrou que a proteção contra a discriminação em razão da deficiência tem como origem e fundamento a vinculação entre igualdade e justiça, mas especialmente a valorização do princípio da igualdade no constitucionalismo após a Segunda Guerra Mundial. Para além de uma igualdade formal, inclui-se a proibição de discriminação (tratamentos desiguais injustificados) e o dever de compensar desigualdades existentes na sociedade.

No Direito Privado, a questão se inclui no âmbito da discussão sobre a eficácia dos direitos fundamentais na ordem privada, pela tensão entre o direito à igualdade e a autonomia privada.

O direito/princípio da igualdade, mesmo quando estabelecido na forma de uma cláusula geral, impõe um ônus argumentativo para o tratamento desigual, já que, prima facie, o tratamento igualitário é exigido. Nessa perspectiva, nem a igualdade de tratamento nem a autonomia privada podem ser considerados direitos ou princípios absolutos, pois sua aplicação nos casos concretos exige um juízo de proporcionalidade acerca da finalidade e dos meios.

É nesse sentido que a cláusula geral de proibição de discriminação produz efeitos também em âmbito privado, uma vez que a autonomia privada é constitucionalmente delimitada 
pela ideia de função social do contrato. A autonomia privada tende a ceder quando as relações entre particulares são realizadas em um contexto de desequilíbrio de poder, o que é especialmente perceptível quando uma das partes pertence a um grupo historicamente excluído pela discriminação, como é o caso das pessoas com deficiência.

No ordenamento jurídico brasileiro pode-se constatar que prevalece uma perspectiva individual de proibição da discriminação, voltada para casos de discriminação direta e assédio, não tendo sido aprofundado o debate doutrinário e jurisprudencial a respeito das medidas de combate à discriminação indireta. Além disso, há uma valorização excessiva da autonomia privada, exigindo-se regulamentação infraconstitucional para aplicação do princípio constitucional da igualdade.

Em relação às pessoas com deficiência, verificou-se a existência de previsões específicas de proibição de discriminação, inclusive no direito infraconstitucional, como nos serviços de saúde, educação, táxi, locação de veículo e construção.

Além dos mecanismos de Direito Privado que são utilizados no combate às práticas discriminatórias em geral, como a imposição do dever de contratação, imposição de abstenções, a nulidade de cláusulas e a indenização por danos extrapatrimoniais, o Estatuto da Pessoa com Deficiência impôs obrigações específicas para determinados serviços, proibiu a cobrança de valores diferenciados e criminalizou práticas discriminatórias.

Contudo, deve-se ressaltar que a discriminação contra a pessoa com deficiência enfrenta a dificuldade de superar posturas e costumes tradicionalmente paternalistas e assistencialistas, que "normalizam" a discriminação sofrida por essas pessoas diariamente.

\section{Referências}

ALEXY, R. Teoria dos Direitos Fundamentais. Tradução: Virgílio Afonso da Silva da $5^{\text {a }}$ edição alemã. São Paulo: Malheiros Editores, 2008.

BRASIL. Decreto $n^{\circ} 3.956$, de 8 de outubro de 2001. Promulga a Convenção Interamericana para a Eliminação de Todas as Formas de Discriminação contra as Pessoas Portadoras de Deficiência. Disponível em: http://www.planalto.gov.br/ccivil_03/decreto/2001/D3956.htm. Acesso em: 23 jan. 2020.

BRASIL. Decreto $n^{\circ}$ 6.949, de 25 de junho de 2009. Promulga a Convenção Internacional sobre os Direitos das Pessoas com Deficiência e seu Protocolo Facultativo, assinados em: Nova York, em: 30 de março de 2007. Disponível em: http://www.planalto.gov.br/ccivil_03/_ato2007-2010/2009/decreto/d6949.htm. Acesso em: 23 jan. 2020.

BRASIL. Lei n 13.146, de 6 de julho de 2015. Institui a Lei Brasileira de Inclusão da Pessoa 
com Deficiência (Estatuto da Pessoa com Deficiência). Disponível em: http://www.planalto.gov.br/ccivil_03/_ato2015-2018/2015/lei/113146.htm. Acesso em 29 jan. 2020.

BRASIL. Supremo Tribunal Federal. Ação direta de inconstitucionalidade nº 5357/DF Distrito Federal. Relator: Ministro Luiz Edson Fachin. Disponível em:

http://redir.stf.jus.br/estfvisualizadorpub/jsp/consultarprocessoeletronico/ConsultarProcessoEl etronico.jsf?seqobjetoincidente=4818214. Acesso em: 12 set. 2017.

FÁVERO, Eugênia Augusta Gonzaga. Direito à educação das pessoas com deficiência.

Revista CEJ, Brasília, v. 8, n. 26, p. 27-35, jul./set. 2004. Disponível em:

http://www.cjf.jus.br/ojs2/index.php/revcej/article/view/621/801. Acesso em: 29 ago. 2017.

FEMINELLA, A. P.; LOPES, L. de F. Disposições Gerais/ Da igualdade e da não

Discriminação e Cadastro-inclusão. In: FAYAN, Regiane Alves Costa; SETUBAL, Joyce Marquezin (Orgs.). Lei Brasileira de Inclusão da Pessoa com Deficiência - Comentada. Campinas: Fundação FEAC, 2016.

INFANTE RUIZ, F. J. El desarollo de la prohibición de no discriminar en el derecho de contratos y su consideración em lá jurisprudencia. Revista de Derecho Patrimonial, n. 30, p. 169-197, 2013.

INFANTE RUIZ, F. J. Igualdad, diversidad y protección contra la discriminación en el derecho privado. In: MARRERO, Carolina Mesa (coord.). Mujeres, Contratos y Empresa desde la Igualdad de Género. Valencia: Tirant lo Blanch, 2013. p. 191-250.

IRTI, N. L'età della decodificazione. 4ª ed. Milano: Giuffrè, 1999.

MARTA, T. N. Pessoas com deficiência X Planos de Saúde: o tratamento desigual que afronta a dignidade humana. Revista Direitos Fundamentais \& Democracia, Curitiba, vol 6, p. 424, jul./dez. 2009. Disponível em:

https://revistaeletronicardfd.unibrasil.com.br/index.php/rdfd/article/view/145. Acesso em: 16 jan. 2020.

MINISTÉRIO PÚBLICO FEDERAL: FUNDAÇÃO PROCURADOR PEDRO JORGE DE MELO E SILVA. O Acesso de Alunos com Deficiência às Escolas e Classes Comuns da Rede Regular. 2. ed. rev. e atual. Brasília: Procuradoria Federal dos Direitos do Cidadão, 2004. Disponível em: http://www.adiron.com.br/arquivos/cartilhaatual.pdf. Acesso em: 11 set. 2017.

PINHEIRO, R. F. A proibição de discriminação nos contratos no direito brasileiro em face da experiência europeia. Revista Direitos Fundamentais \& Justiça, ano 8, no 28, p. 52-81, jul./set. 2014. Disponível em: http://dfj.emnuvens.com.br/dfj/article/view/210/793. Acesso em 28 jan. 2020.

RIOS, R. R.; LEIVAS, P. G. C.; SCHÄFER, G. Direito da antidiscriminação e direitos de minorias: perspectivas e modelos de proteção individual e coletivo. Revista Direitos Fundamentais \& Democracia, v. 22, n. 1, p. 126-148, jan./abr. 2017. Disponível em: https://revistaeletronicardfd.unibrasil.com.br/index.php/rdfd/article/view/852. Acesso em: 16 jan. 2020 
RULL, A. A. Discriminación Directa e Indirecta. InDret. Revista per a l'anàlisi del dret. Barcelona, 396, p. 1-18, ene. 2007. Disponível em: http://www.indret.com/pdf/396_es.pdf. Acesso em 29 jan. 2020.

SALES, G. B.; SARLET, I. W. A igualdade na Constituição Federal de 1988: um ensaio acerca do sistema normativo brasileiro face à Convenção Internacional e à Lei Brasileira de Inclusão da Pessoa com Deficiência (Lei 13.146/2015). In: MENEZES, Joyceane Bezerra de (Org.). Direito das Pessoas com Deficiência Psíquica e Intelectual nas Relações Privadas: Convenção Sobre os Direitos da Pessoa com Deficiência e Lei Brasileira de Inclusão. 2. ed. rev. e ampl. Rio de Janeiro: Editora Processo, 2020. p. 197-224

SANTOS, B. de S. Uma concepção multicultural de direitos humanos. Lua Nova: Revista de Cultura e Política, $n^{\circ}$ 39, p. 105-201, 1997. Disponível em: http://www.scielo.br/scielo.php?script=sci_arttext\&pid=S0102$64451997000100007 \& \operatorname{lng}=\mathrm{es} \& n r m=$ iso\&tlng=pt. Acesso em 17 jul. 2016.

SARLET, I. W. Direitos fundamentais sociais, "mínimo existencial" e direito privado: breves notas sobre alguns aspectos da possível eficácia dos direitos sociais nas relações entre particulares. In: SARMENTO, Daniel; GALDINO, Flávio. (Orgs.) Direitos Fundamentais: estudos em homenagem ao professor Ricardo Lobo Torres. Rio de Janeiro: Renovar, 2006. p. 551-602.

SILVA, J. C. F. da. A proteção contra discriminação no direito contratual brasileiro. In: MONTEIRO, António Pinto; NEUNER, Jörg; SARLET, Ingo Wolfgang (org.). Direitos fundamentais e Direito Privado. Uma perspectiva de direito comparado. Coimbra: Almedina, 2007. p. 389-416.

TRAUTWEIN, J. R. D. T.; PINHEIRO, R. F. A educação inclusiva e a proibição de discriminação da pessoa com deficiência: desvendando a ação direta de inconstitucionalidade $\mathrm{n}^{\mathrm{o}} 5.357$ do supremo tribunal federal. Revista Jurídica Direito \& Paz. Lorena, ano IX, n. 36, p. $195-216,1^{\circ}$ sem. 2017. 